\title{
Low Alanine Aminotransferase as a Risk Factor for Chronic Obstructive Pulmonary Disease in Males: A Retrospective Population-based Cohort Study
}

\section{Yong Jun Choi}

Department of Internal Medicine, Gangnam Severance Hospital, Yonsei University College of Medicine, Seoul

\section{Do Sun Kwon}

Department of Internal Medicine, Gangnam Severance Hospital, Yonsei University College of Medicine, Seoul

\section{Taehee Kim}

Department of Internal Medicine, Gangnam Severance Hospital, Yonsei University College of Medicine, Seoul

\section{Jae Hwa Cho}

Department of Internal Medicine, Gangnam Severance Hospital, Yonsei University College of Medicine, Seoul

\section{Hyung Jung Kim}

Department of Internal Medicine, Gangnam Severance Hospital, Yonsei University College of Medicine, Seoul

\section{Min Kwang Byun}

Department of Internal Medicine, Gangnam Severance Hospital, Yonsei University College of Medicine, Seoul

\section{Hye Jung Park ( $\square$ craft7820@yuhs.ac )}

Department of Internal Medicine, Gangnam Severance Hospital, Yonsei University College of Medicine, Seoul

\section{Research Article}

Keywords: alanine aminotransferase, chronic obstructive pulmonary disease, risk factor, serologic marker

Posted Date: February 18th, 2021

DOl: https://doi.org/10.21203/rs.3.rs-206981/v1

License: (c) (i) This work is licensed under a Creative Commons Attribution 4.0 International License. Read Full License 
Version of Record: A version of this preprint was published at Scientific Reports on July 21st, 2021. See the published version at https://doi.org/10.1038/s41598-021-94385-0. 


\section{Abstract}

Alanine aminotransferase (ALT) levels reflect skeletal muscle volume and general performance scales, which are significantly associated with chronic obstructive pulmonary disease (COPD) development and prognosis. The aim of this study was to investigate the ALT levels as a risk factor for COPD development. This 13-year population-based retrospective cohort observational study included patients registered in the health check-up cohort database of the Korean National Health Insurance Service. A total of 422,452 participants were analysed. We classified groups according to the baseline ALT levels (groups $1-5$ : ALT (IU/L) $<10 ; 10-19 ; 20-$ 29; 30-39; and $\geq 40$, respectively). The incidence of COPD was highest in group 1, decreasing as the group number increased among in males. Cox regression analysis in males revealed that lower ALT level was a significant risk factor for COPD development (univariable, HR: 0.992, 95\% Cl: 0.991-0.994; multivariable, HR: 0.998, 95\% Cl: 0.996-0.999). In addition, in the low ALT level groups (< $40 \mathrm{IU} / \mathrm{L})$, COPD was more likely to be developed (univariable, HR: 1.341, 95\% Cl: 1.263-1.424; multivariable, HR: 1.097, 95\% Cl: 1.030-1.168). Our findings suggest that males with low ALT levels should be carefully monitored for COPD development.

\section{Introduction}

Chronic obstructive pulmonary disease (COPD) is a chronic airway disease requiring life-long management. COPD has contributed to an enormous socioeconomic burden worldwide [1]. Early detection of COPD can lead to appropriately timed treatment, prevention of airway remodelling in early stages, and improvements of symptoms and prognosis of COPD [2,3]. Determining risk factors predicting COPD development aids in the early detection of COPD. To date, we know that heavy smoking history, old age, male sex, and other epidemiologic factors contribute to COPD development $[4,5]$.

Alanine aminotransferase (ALT) levels can be easily measured from serum and are commonly used to evaluate liver disease [6]. However, recent studies have revealed that low ALT levels predict poor health outcomes, including death, and reflect skeletal muscle volume; these are important factors representing general condition and performance in old age [7-13]. In particular, decreased skeletal muscle volume is an important risk factor for COPD development $[14,15]$. Therefore, low ALT levels might adversely affect COPD development. Moreover, recent studies have revealed that liver diseases, such as non-alcoholic fatty liver disease, affect COPD development and prognosis. Therefore, high ALT levels might also adversely affect COPD [16-18].

This study aimed to investigate the role of serum ALT levels in predicting COPD development, after excluding the effects of liver diseases, using a large, nation-wide, population-based cohort database.

\section{Results}

\section{Baseline clinical characteristics}

The 422,452 participants were divided into five groups based on the serum ALT levels at the time of the health check-up. The baseline characteristics of each group are described in Table 1. Most variables in the results were associated with the ALT group. The proportion of females was higher in groups 1 and 2 (76.7\% 
and $62.2 \%$, respectively). However, the proportion of females was lower in groups 3 , 4 , and $5(39.7 \%, 27.6 \%$, and $21.7 \%$, respectively; $P<0.0001)$. Smoking status was also significantly different according to the ALT level. The proportion of current smokers was higher in group $5(34.2 \%)$ than in groups $1(11.9 \%)$ and 2

$(17.4 \%)(P<0.0001)$. The percentage of participants who did not exercise was higher in group $1(59.4 \%)$ than in the other groups, especially group $5(51.7 \%)(P<0.001)$. Participants in group 1 were younger and had a lower BMl, blood pressure, hemoglobin level, fasting glucose level, and total cholesterol level than values in the other groups $(P<0.0001)$. 
Table 1

Baseline characteristics of participants according to serum ALT levels

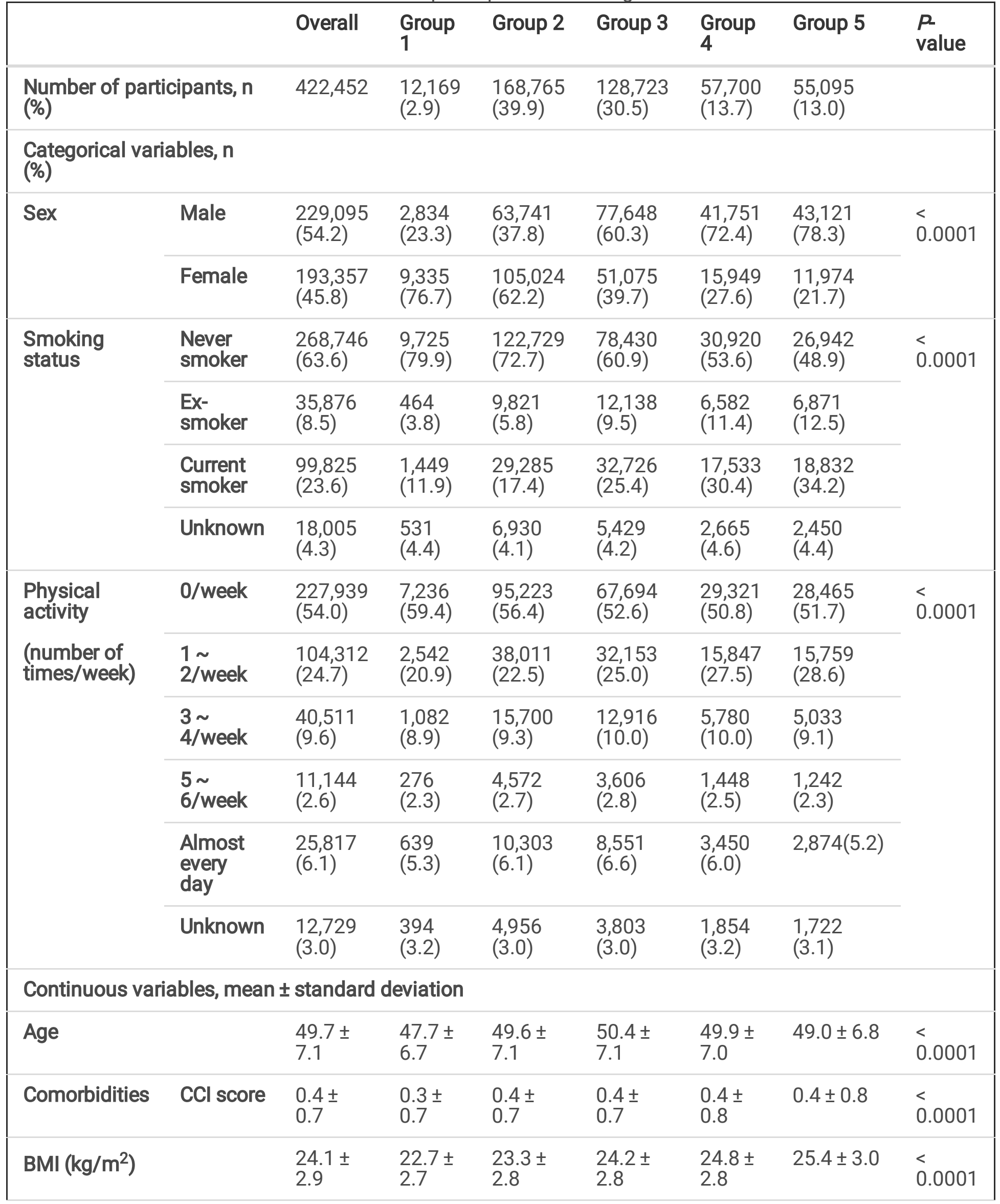




\begin{tabular}{|c|c|c|c|c|c|c|c|c|}
\hline & & Overall & $\begin{array}{l}\text { Group } \\
1\end{array}$ & Group 2 & Group 3 & $\begin{array}{l}\text { Group } \\
4\end{array}$ & Group 5 & $\begin{array}{l}P \\
\text { value }\end{array}$ \\
\hline \multicolumn{2}{|c|}{$\begin{array}{l}\text { Systolic blood pressure } \\
(\mathrm{mmHg})\end{array}$} & $\begin{array}{l}125.8 \pm \\
17.7\end{array}$ & $\begin{array}{l}120.2 \\
\pm 17.1\end{array}$ & $\begin{array}{l}123.1 \pm \\
17.3\end{array}$ & $\begin{array}{l}126.8 \pm \\
17.6\end{array}$ & $\begin{array}{l}128.7 \\
\pm 17.5\end{array}$ & $\begin{array}{l}130.1 \pm \\
17.4\end{array}$ & $<.0001$ \\
\hline \multicolumn{2}{|c|}{$\begin{array}{l}\text { Diastolic blood pressure } \\
\text { (mmHg) }\end{array}$} & $\begin{array}{l}79.4 \pm \\
11.7\end{array}$ & $\begin{array}{l}75.6 \pm \\
11.4\end{array}$ & $\begin{array}{l}77.4 \pm \\
11.5\end{array}$ & $\begin{array}{l}80.0 \pm \\
11.6\end{array}$ & $\begin{array}{l}81.5 \pm \\
11.6\end{array}$ & $\begin{array}{l}82.5 \pm \\
11.6\end{array}$ & $<.0001$ \\
\hline \multicolumn{2}{|c|}{ Hemoglobin (g/dL) } & $\begin{array}{l}14.0 \pm \\
1.5\end{array}$ & $\begin{array}{l}12.9 \pm \\
1.6\end{array}$ & $\begin{array}{l}13.5 \pm \\
1.5\end{array}$ & $\begin{array}{l}14.1 \pm \\
1.4\end{array}$ & $\begin{array}{l}14.5 \pm \\
1.4\end{array}$ & $14.7 \pm 1.4$ & $<.0001$ \\
\hline \multicolumn{2}{|c|}{$\begin{array}{l}\text { Fasting blood glucose } \\
\text { (mg/dL) }\end{array}$} & $\begin{array}{l}97.4 \pm \\
33.7\end{array}$ & $\begin{array}{l}91.7 \pm \\
28.5\end{array}$ & $\begin{array}{l}94.1 \pm \\
30.7\end{array}$ & $\begin{array}{l}97.9 \pm \\
34.1\end{array}$ & $\begin{array}{l}100.6 \\
\pm 36.2\end{array}$ & $\begin{array}{l}104.4 \pm \\
38.2\end{array}$ & $<.0001$ \\
\hline \multicolumn{2}{|c|}{ Total cholesterol (mg/dL) } & $\begin{array}{l}200.3 \pm \\
38.3\end{array}$ & $\begin{array}{l}187.5 \\
\pm 37.0\end{array}$ & $\begin{array}{l}195.2 \pm \\
36.3\end{array}$ & $\begin{array}{l}202.1 \pm \\
37.6\end{array}$ & $\begin{array}{l}205.9 \\
\pm 39.2\end{array}$ & $\begin{array}{l}208.6 \pm \\
41.9\end{array}$ & $<.0001$ \\
\hline \multirow[t]{3}{*}{$\begin{array}{l}\text { Liver function } \\
\text { test }\end{array}$} & $\begin{array}{l}\text { AST } \\
\text { (IU/L) }\end{array}$ & $\begin{array}{l}26.6 \pm \\
17.1\end{array}$ & $\begin{array}{l}17.9 \pm \\
19.8\end{array}$ & $\begin{array}{l}20.6 \pm \\
6.0\end{array}$ & $\begin{array}{l}25.2 \pm \\
7.5\end{array}$ & $\begin{array}{l}30.0 \pm \\
10.5\end{array}$ & $\begin{array}{l}46.2 \pm \\
35.5\end{array}$ & $<.0001$ \\
\hline & $\begin{array}{l}\text { ALT } \\
\text { (IU/L) }\end{array}$ & $\begin{array}{l}26.2 \pm \\
21.3\end{array}$ & $\begin{array}{l}7.8 \pm \\
1.4\end{array}$ & $\begin{array}{l}15.0 \pm \\
2.7\end{array}$ & $\begin{array}{l}23.9 \pm \\
2.8\end{array}$ & $\begin{array}{l}33.7 \pm \\
2.8\end{array}$ & $\begin{array}{l}61.8 \pm \\
40.3\end{array}$ & $<.0001$ \\
\hline & $\begin{array}{l}\mathbb{\nabla G T} \\
(\mathrm{IU} / \mathrm{L})\end{array}$ & $\begin{array}{l}36.9 \pm \\
49.9\end{array}$ & $\begin{array}{l}16.0 \pm \\
15.1\end{array}$ & $\begin{array}{l}21.1 \pm \\
17.1\end{array}$ & $\begin{array}{l}33.5 \pm \\
30.9\end{array}$ & $\begin{array}{l}48.8 \pm \\
46.5\end{array}$ & $\begin{array}{l}85.1 \pm \\
101.5\end{array}$ & $<.0001$ \\
\hline
\end{tabular}

\section{ALT level and incidence of COPD development}

The prevalence of newly developed COPD in the study population over the 13-year period was $3.5 \%(n=$ 14,656). Comparing the five groups according to serum ALT levels, the prevalence of newly developed COPD was $2.8 \%, 3.3 \%, 3.8 \%, 3.7 \%$, and $3.1 \%$, respectively $(P<0.0001$; Fig. $2 A)$. There was also no consistent correlation between ALT groups and COPD development in cumulative incidence (Fig. 2C).

We conducted a subgroup analysis according to sex and smoking status. In male participants, COPD development was the most prevalent in group 1 , decreasing as the group number increased $(4.2 \%, 4.2 \%, 3.9 \%$, $3.5 \%$, and $2.9 \%$, respectively; $P<0.0001$ ). Conversely, in female participants, COPD development was the most prevalent in group 4, decreasing as the group number decreased except for group 5 (2.3\% in group 1, 2.8\% in group $2,3.7 \%$ in group $3,4.1 \%$ in group 4 , and $3.7 \%$ in group $5 ; P<0.0001$ ). In comparing the cumulative incidence of COPD, the steepness of the slopes of the Kaplan-Meier curves in male participants increased as the group number decreased; however, these values were not sequential in female participants (Fig. 2D and $2 \mathrm{E})$.

Among the subgroups divided according to smoking status, a negative correlation with COPD prevalence was only observed in the current smoker group (5.4\% in group $1,5.0 \%$ in group $2,4.5 \%$ in group $3,3.9 \%$ in group 4 , and $3.3 \%$ in group $5 ; P<0.0001)$. In the other subgroups, the results were similar to the patterns observed in female participants (Fig. 2B). The steepness of the slopes of the Kaplan-Meier curves for cumulative COPD development in current smokers increased as the group number decreased; however, these values were not sequential in the other groups (Fig. $2 \mathrm{~F}-\mathrm{H}$ ). 


\section{ALT level as a risk factor for COPD development}

Univariable and multivariable Cox regression analyses revealed that old age, male sex, smoking, comorbidities, lack of exercise, low systolic blood pressure and lower ALT levels were significant risk factors for COPD development (HR: 0.998, 95\% Cl: 0.997-0.999, $P<0.0001$; Supplementary Table 1). To assess whether ALT level was related to other variables that are already well-established risk factors for COPD development, correlation coefficients of each variables were analysed and drawn as a graph (Supplementary Fig. 1A). ALT showed a strong association with other liver function tests (AST, \GT); however, it did not show an apparent association with other risk factors for COPD development at baseline. Male sex was highly associated with current smoking; therefore, subgroup analysis was conducted according to sex and smoking status to assess specific factors that more strongly explained the association between low ALT and COPD.

In males, lower ALT level was a significant risk factor for COPD development according to the multivariable Cox regression analysis (HR: 0.998, 95\% Cl: 0.996-0.999, $P=0.0001$; Supplementary Table 2). However, in females, the ALT level was not a significant risk factor for COPD development (HR: 1.000, 95\% Cl: 0.999$1.002, P=0.8068$; Supplementary Table 3). In both males and females, correlation coefficients of each variables were also analysed to identify the link between ALT level and other risk factors for COPD. The ALT level did not show an apparent association with other risk factors for COPD development (Supplementary Fig. 1B and 1C).

A subgroup analysis according to smoking status revealed a similar pattern. In the current smoker subgroup, the lower ALT level was a significant risk factor for COPD development (HR: $0.996,95 \% \mathrm{Cl}: 0.994-0.998, P=$ 0.0002; Supplementary Table 4). However, ALT level was not significant in never smokers (HR: $1.000,95 \% \mathrm{Cl}$ : 0.998-1.001, $P=0.4678$; Supplementary Table 5).

Spline curves between ALT and HRs for COPD development were compared according to smoking status in each sex group (Fig. 3). Same as previous results, in all participants and females, the curves did not show a consistent correlation between the ALT levels and HR for COPD development (Fig. 3A and 3C, respectively). By contrast, curves of males showed negative correlation between ALT and HRs of COPD development (Fig. 3B).

In current smoker group, the curves of all and male current smokers showed negative correlation between ALT and HRs of COPD development (Fig. 3D and E, respectively), by contrast, the curves of female currents smokers did not show a consistent correlation (Fig. 3F). In never smokers, only curve of male never smokers showed negative correlation, other groups did not show a consistent correlation (Fig. 3H, Fig. 3G, and Fig. 3l, respectively). Based on these results, it was suggested that ALT is a significant risk factor in males rather than in current smokers.

We redefined groups 1 through 4 and 5 as low and high ALT groups in males, respectively. Comparisons between two groups are described in Supplementary Table 6. As with the baseline characteristics of all participants, most variables were associated with ALT levels. 
Additional Cox regression analysis showed that in males, low ALT levels was a significant risk factor for COPD development in both univariable Cox regression analysis (HR: 1.341, 95\% Cl: 1.263-1.424, $P<0.0001$ ) and multivariable Cox regression analysis (HR: 1.097, 95\% Cl: 1.030-1.168, $P=0.0042)$ (Fig. 4). The KaplanMeier curves for cumulative COPD development in the two groups also showed a significant difference. In the low ALT group, the cumulative incidence of COPD was higher than in the high ALT group ( $3.9 \%$ vs. $2.9 \%, P<$ 0.0001 , Fig. 5).

\section{Discussion}

To our knowledge, this is the first study to find that a lower serum ALT level is a risk factor for COPD development in males. We believe that ALT levels reflect overall health status, as described previously [10]. Therefore, the HR of ALT levels became weaker after adjusting for other risk factors. However, low ALT levels were still an independent risk factor for COPD development after adjusting for the other factors.

We also observed that the effects of ALT level on COPD development differed according to sex. Previous studies have described the association between ALT levels and obesity. Fat accumulation accelerates chronological ageing of liver cells, increasing the vulnerability of the liver cells to oxidative stress and energy metabolic pressure, thus increasing liver enzyme levels [19-21]. However, this process can differ in males and females [22,23]. Since sex hormones affect fat and muscle distributions, the subcutaneous fat storage capacity is lower in males than in females. Therefore, in males, fat more accumulates in other tissues, including the viscera and liver, rather than subcutaneous tissue, which may lead to greater fat accumulation in the liver in the early stages of obesity. As a result, serum ALT levels may be elevated even in the early stages of obesity [21,24-27]. Therefore, ALT levels in males may have a stronger relationship with fat accumulation associated with general nutrition, performance scales, and health status than that in females. This might explain why the effects of ALT levels on COPD development are more substantial in males. However, it is thought that further studies will be needed to establish the exact relationship between ALT level and COPD.

The effects of ALT levels on COPD development were more prominent in male current smokers than in male never smokers. The relationship between smoking status and ALT levels is also unclear. Breitling et al. [28] implied a trend towards a significant negative association between smoking intensity and serum ALT levels in non-drinkers in a cross-sectional study. Most other studies have also observed an inverse association or the lack of an association between smoking and ALT levels [28-31]. However, it is known that males and current smokers are more susceptible to developing COPD. We surmise that the effect of ALT level on COPD in male current smokers was accentuated in these vulnerable subgroups.

According to a recent literature review, COPD is underdiagnosed in $65-80 \%$ of participants with chronic airflow limitations. [32] To control the disease effectively, early diagnosis and treatment of COPD are vital for preventing airway remodelling in the early stages. [2,3] Meanwhile, ALT level is a commonly performed test that is inexpensive, easy to obtain from serum, and included in most basic chemical tests. Therefore, this study suggests careful monitoring of males with low ALT levels, which may be helpful in the early detection of COPD and improved COPD prognosis in these individuals. 
Our study had several limitations. First, we divided the participants into five groups based on ALT intervals of $10 \mathrm{IU} / \mathrm{L}$, aligning with previous studies, because there are no reference cut-off values for low ALT levels [12]. Second, the diagnosis of COPD in our study was based on ICD-10 codes and prescribed medication data from the NHIS database, without pulmonary function testing. Similarly, we also defined liver disease based on the ICD-10 codes. Despite these limitations, our study had several strengths. Above all, it was the first study, to our knowledge, to investigate the relationship between serum ALT levels and COPD development. Moreover, it was a long-term cohort study, which allowed us to analyse the risk factors potentially affecting COPD development. Finally, the results had high statistical power owing to the large-scale analysis involving 422,452 participants.

\section{Conclusions}

The current results suggest that low serum ALT levels may play a significant role in COPD development in males. Therefore, clinicians should carefully monitor male patients with low ALT levels for COPD development.

\section{Methods}

\section{Study design and population}

This retrospective cohort study was conducted in a health check-up cohort population from the Korean National Health Insurance Service (NHIS) database. In South Korea, populations aged 40-79 years participated in the biennial national health screening programme covered by the Korean National Health Insurance cooperation. This cohort group is a simple random sample representing $10 \%$ of the 5.15 million populations who participated in the national health screening programme from 2002 to 2003.

Among the 514,844 participants, 73,404 participants aged above 65 years were excluded to reduce the confounding effects of extreme old age on the development of COPD; 3,857 were excluded owing to a diagnosis of COPD at the time of the health check-up; and 15,131 were excluded due to diagnoses of liver disease such as viral liver disease, non-alcoholic fatty liver disease, and hepatocellular carcinoma at the time of the health check-up, to limit the confounding effects of liver disease on ALT levels. Finally, 422,452 participants were included in the analysis (Figure 1).

Participants were divided into five groups, based on serum ALT levels at baseline: group 1, ALT (IU/L) < 10; group 2, $10 \leq A L T<20$; group 3, $20 \leq A L T<30$; group 4, $30 \leq A L T<40$; and group 5, ALT $\geq 40$. COPD development was retrospectively compared among all groups for 13 years.

\section{Parameters included in data collection}

The basic demographic data included participants' age and sex, and insurance claim data included the dates of hospital visits, diagnostic codes encoded by the ICD-10, and prescriptions. Charlson's comorbidity index was calculated based on comorbidities using ICD-10 codes [33]. Health check-up data provided the results of 
the health check-ups conducted in 2002 or 2003 and included the results of body mass index $\left(\mathrm{BMl} ; \mathrm{kg} / \mathrm{m}^{2}\right)$ and systolic and diastolic blood pressure $(\mathrm{mmHg})$ measurements, as well as hemoglobin $(\mathrm{g} / \mathrm{dL})$, fasting blood glucose $(\mathrm{mg} / \mathrm{dL})$, total cholesterol $(\mathrm{mg} / \mathrm{dL})$, aspartate aminotransferase (AST; IU/L), ALT (IU/L), and gamma-glutamyl transferase ( $\mathbb{G} \mathrm{GT}$; IU/L) levels. Moreover, health check-up data included a self-report questionnaire, which the participants answered during the health check-up, providing information regarding smoking status (never smoker, ex-smoker, and current smoker) and physical activity (0, 1-2, 3-4, 5-6 times/week, and almost every day).

\section{Definition of COPD development}

As the NHIS database does not include data from pulmonary function tests, we defined COPD development based on the diagnostic codes of the ICD-10 and prescriptions contained in the insurance claim data, as suggested by previous studies [34-36]. COPD development was determined when all of the following criteria were met: 1) age above 40 years; 2) ICD-10 diagnostic code of COPD or emphysema (J43.0x-J44.X, except J43.0, as the primary or secondary diagnosis [within the fourth position]); 3 ) the use of COPD medications, including a muscarinic antagonist, beta- 2 agonist, inhaled corticosteroid, phosphodiesterase- 4 inhibitor, or methylxanthine; and 4) first diagnosis of COPD in the follow-up period.

\section{Definition of liver disease}

Liver diseases were defined using diagnostic codes. The following ICD-10 codes were used in this study to exclude the effects of these underlying liver diseases on ALT levels: K70.X-K77.x, disease of liver; B15.XB19.x, viral hepatitis; E83.0, Wilson disease; and C22.0, liver cell carcinoma.

\section{Statistical analysis}

To compare baseline characteristics across groups, chi-squared tests were used for categorical variables, and paired t-test or one-way analyses of variance with Bonferroni post-hoc tests were used for continuous variables. Univariable and multivariable Cox regression analyses were performed to evaluate the hazard ratio (HR) of each variable for COPD development. A subgroup analysis was performed according to sex and smoking status. Kaplan-Meier curves were drawn to evaluate the cumulative incidence of COPD among the groups according to serum ALT levels. P-values $<0.05$ were considered to indicate statistical significance. Statistical analyses were conducted with R (version 3.3.3; R Foundation for Statistical Computing, Vienna, Austria) software. Furthermore, spline curves of the HRs for COPD development were drawn using the pspline $\mathrm{R}$ package, and correlation coefficient plot were drawn using the corrplot $\mathrm{R}$ package.

\section{List Of Abbreviations}

ALT, alanine aminotransferase

AST, aspartate aminotransferase 
BMI, body mass index

$\mathrm{Cl}$, confidence interval

COPD, chronic obstructive pulmonary disease

\GT, gamma-glutamyl transferase

HR, hazard ratio

ICD-10, International Classification of Disease, 10th edition

NHIS, National Health Insurance Service

\section{Declarations}

\section{Ethics approval and consent to participate}

This study used NHIS-NSC data (NHIS-2019-2-183) provided by the NHIS. The study was approved by the Institutional Review Board of Gangnam Severance Hospital (number: 3-2019-0123). The data from NIHS contained no personal information, the need for informed consent was waived. The Institutional Review Board of Gangnam Severance Hospital approved the waiver of the informed consent. All data were collected in accordance with the amended Declaration of Helsinki. The authors declare no conflict of interest with NHIS.

\section{Consent for publication}

Not applicable

\section{Availability of data and materials}

The data that support the findings of this study are available from NHIS. Restrictions apply to the availability of these data, which were used under license for this study. Data are available at URL: https://nhiss.nhis.or.kr with the permission of NHIS.

\section{Competing interests}

The authors declare that they have no competing interests

\section{Funding}

The authors received no financial support for the research, authorship, and/or publication of this article. 


\section{Author contributions}

YJC had full access to all of the data in the study and takes responsibility for the integrity of the data and the accuracy of the data analysis. HJP was the principal investigator and contributed substantially to the study design, data collection, analysis and interpretation, and writing of the manuscript. She personally reviewed the efficacy data, understands the statistical methods employed for the efficacy analysis, and confirms an understanding of this analysis; she also confirms that the methods are clearly described and that the results have been reported in a fair manner. DSK, TK, JHC, HJK, and MKB contributed substantially to the study design, data analysis and interpretation, and the writing of the manuscript.

The authors thank MID (Medical Illustration \& Design), a part of the Medical Research Support Services of Yonsei University College of Medicine, for all artistic support related to this work.

\section{References}

1. Park YB, Rhee CK, Yoon HK, Oh YM, Lim SY, Lee JH, et al. Revised (2018) COPD Clinical Practice Guideline of the Korean Academy of Tuberculosis and Respiratory Disease: A Summary. Tuberc Respir Dis (Seoul). 2018;81(4):261-73.

2. Csikesz NG, Gartman EJ. New developments in the assessment of COPD: early diagnosis is key. Int J Chron Obstruct Pulmon Dis. 2014;9:277-86.

3. Welte T, Vogelmeier C, Papi A. COPD: early diagnosis and treatment to slow disease progression. Int J Clin Pract. 2015;69(3):336-49.

4. Hikichi M, Hashimoto S, Gon Y. Asthma and COPD overlap pathophysiology of ACO. Allergol Int. 2018;67(2):179-86.

5. Ding Y, Xu J, Yao J, Chen Y, He P, Ouyang Y, et al. The analyses of risk factors for COPD in the Li ethnic group in Hainan, People's Republic of China. Int J Chron Obstruct Pulmon Dis. 2015;10:2593-600.

6. Sherman KE. Alanine Aminotransferase in Clinical Practice. Archives of Internal Medicine. 1991;151(2):260-5.

7. Irina G, Refaela C, Adi B, Avia D, Liron H, Chen A, et al. Low Blood ALT Activity and High FRAIL Questionnaire Scores Correlate with Increased Mortality and with Each Other. A Prospective Study in the Internal Medicine Department. J Clin Med. 2018;7(11).

8. Vespasiani-Gentilucci U, De Vincentis A, Ferrucci L, Bandinelli S, Antonelli Incalzi R, Picardi A. Low Alanine Aminotransferase Levels in the Elderly Population: Frailty, Disability, Sarcopenia, and Reduced Survival. J Gerontol A Biol Sci Med Sci. 2018;73(7):925-30.

9. Liu Z, Que S, Xu J, Peng T. Alanine aminotransferase-old biomarker and new concept: a review. Int J Med Sci. 2014;11(9):925-35.

10. Kim WR, Flamm SL, Di Bisceglie AM, Bodenheimer HC. Serum activity of alanine aminotransferase (ALT) as an indicator of health and disease. Hepatology. 2008;47(4):1363-70.

11. Yamazaki H, Kamitani T, Matsui T, Yamamoto Y, Fukuhara S. Association of low alanine aminotransferase with loss of independence or death: A 5-year population-based cohort study. J 
Gastroenterol Hepatol. 2019; doi:10.1111/jgh.14631.

12. Oh CM, Won YJ, Cho H, Lee JK, Park BY, Jun JK, et al. Alanine aminotransferase and gamma-glutamyl transferase have different dose-response relationships with risk of mortality by age. Liver Int. 2016;36(1):126-35.

13. Lee TH, Kim WR, Benson JT, Therneau TM, Melton LJ, 3rd. Serum aminotransferase activity and mortality risk in a United States community. Hepatology. 2008;47(3):880-7.

14. Costa TM, Costa FM, Moreira CA, Rabelo LM, Boguszewski CL, Borba VZ. Sarcopenia in COPD: relationship with COPD severity and prognosis. J Bras Pneumol. 2015;41(5):415-21.

15. Byun MK, Cho EN, Chang J, Ahn CM, Kim HJ. Sarcopenia correlates with systemic inflammation in COPD. Int J Chron Obstruct Pulmon Dis. 2017;12:669-75.

16. Moon SW, Kim SY, Jung JY, Kang YA, Park MS, Kim YS, et al. Relationship between obstructive lung disease and non-alcoholic fatty liver disease in the Korean population: Korea National Health and Nutrition Examination Survey, 2007-2010. Int J Chron Obstruct Pulmon Dis. 2018;13:2603-11.

17. Viglino D, Jullian-Desayes I, Minoves M, Aron-Wisnewsky J, Leroy V, Zarski JP, et al. Nonalcoholic fatty liver disease in chronic obstructive pulmonary disease. Eur Respir J. 2017;49(6).

18. Minakata Y, Ueda H, Akamatsu K, Kanda M, Yanagisawa S, Ichikawa T, et al. High COPD prevalence in patients with liver disease. Intern Med. 2010;49(24):2687-91.

19. Horvath S, Erhart W, Brosch M, Ammerpohl O, von Schonfels W, Ahrens M, et al. Obesity accelerates epigenetic aging of human liver. Proc Natl Acad Sci U S A. 2014;111(43):15538-43.

20. Horvath S. DNA methylation age of human tissues and cell types. Genome Biol. 2013;14(10):R115.

21. Xu L, Jiang CQ, Schooling CM, Zhang WS, Cheng KK, Lam TH. Liver enzymes as mediators of association between obesity and diabetes: the Guangzhou Biobank Cohort Study. Ann Epidemiol. 2017;27(3):204-7.

22. Brown LM, Gent L, Davis K, Clegg DJ. Metabolic impact of sex hormones on obesity. Brain research. 2010;1350:77-85.

23. Sáez-López C, Salcedo-Allende MT, Hernandez C, Simó-Servat O, Simó R, Selva DM. Sex HormoneBinding Globulin Expression Correlates With Acetyl-Coenzyme A Carboxylase and Triglyceride Content in Human Liver. The Journal of Clinical Endocrinology \& Metabolism. 2018;104(5):1500-7.

24. Ahn MB, Bae WR, Han KD, Cho WK, Cho KS, Park SH, et al. Association between serum alanine aminotransferase level and obesity indices in Korean adolescents. Korean J Pediatr. 2015;58(5):165-71.

25. Sattar N. Gender aspects in type 2 diabetes mellitus and cardiometabolic risk. Best Pract Res Clin Endocrinol Metab. 2013;27(4):501-7.

26. Wu L, He Y, Jiang B, Liu M, Yang S, Wang Y, et al. Gender difference in the association between aminotransferase levels and hypertension in a Chinese elderly population. Medicine (Baltimore). 2017;96(21):e6996.

27. Buday B, Pach PF, Literati-Nagy B, Vitai M, Kovacs G, Vecsei Z, et al. Sex influenced association of directly measured insulin sensitivity and serum transaminase levels: Why alanine aminotransferase only predicts cardiovascular risk in men? Cardiovasc Diabetol. 2015;14:55. 
28. Breitling LP, Arndt V, Drath C, Brenner H. Liver enzymes: interaction analysis of smoking with alcohol consumption or BMI, comparing AST and ALT to gamma-GT. PLoS One. 2011;6(11):e27951.

29. Robinson D, Whitehead TP. Effect of body mass and other factors on serum liver enzyme levels in men attending for well population screening. Ann Clin Biochem. 1989;26 (Pt 5):393-400.

30. Tajima K, Takeuchi K, Suzuki S. Risk Factors for Liver Dysfunction in Middle Aged Men based on Four Year Health Examination Data. Journal of Occupational Health. 1998;40(4):339-44.

31. Wannamethee SG, Shaper AG. Cigarette smoking and serum liver enzymes: the role of alcohol and inflammation. Ann Clin Biochem. 2010;47(Pt 4):321-6.

32. Diab N, Gershon AS, Sin DD, Tan WC, Bourbeau J, Boulet LP, et al. Underdiagnosis and Overdiagnosis of Chronic Obstructive Pulmonary Disease. Am J Respir Crit Care Med. 2018;198(9):1130-9.

33. Charlson ME, Pompei P, Ales KL, MacKenzie CR. A new method of classifying prognostic comorbidity in longitudinal studies: development and validation. J Chronic Dis. 1987;40(5):373-83.

34. Park HJ, Cho JH, Kim HJ, Park JY, Lee HS, Byun MK. The effect of low body mass index on the development of chronic obstructive pulmonary disease and mortality. J Intern Med. 2019; doi:10.1111/joim.12949.

35. Chung SM, Lee SY. Evaluation of Appropriate Management of Chronic Obstructive Pulmonary Disease in Korea: Based on Health Insurance Review and Assessment Service (HIRA) Claims. Tuberc Respir Dis (Seoul). 2017;80(3):241-6.

36. Lee J, Lee JH, Kim JA, Rhee CK. Trend of cost and utilization of COPD medication in Korea. Int J Chron Obstruct Pulmon Dis. 2017;12:27-33.

\section{Figures}




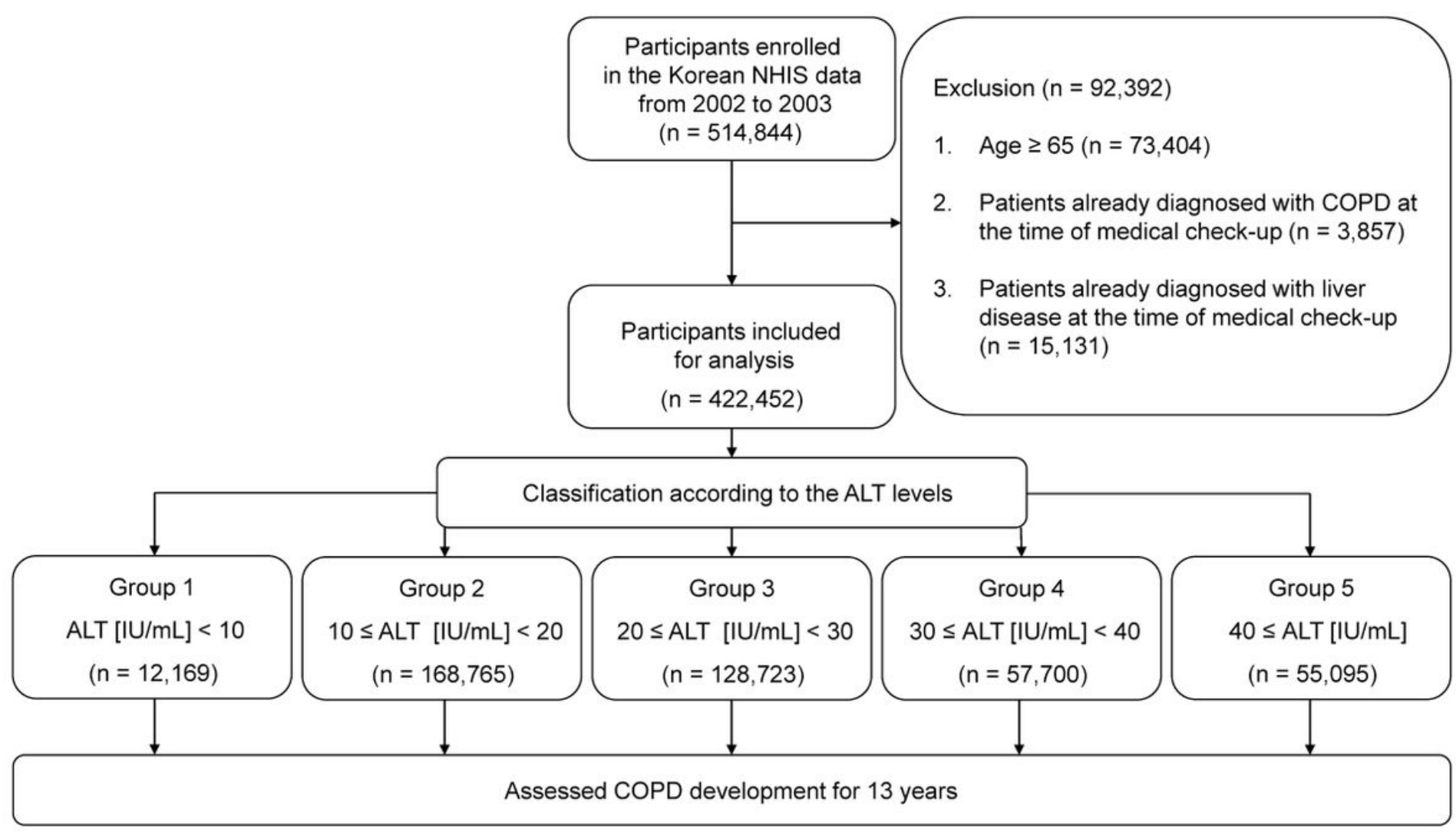

\section{Figure 1}

Study flowchart. ALT, alanine aminotransferase; COPD, chronic obstructive pulmonary disease; NHIS, National Health Insurance Survey. 

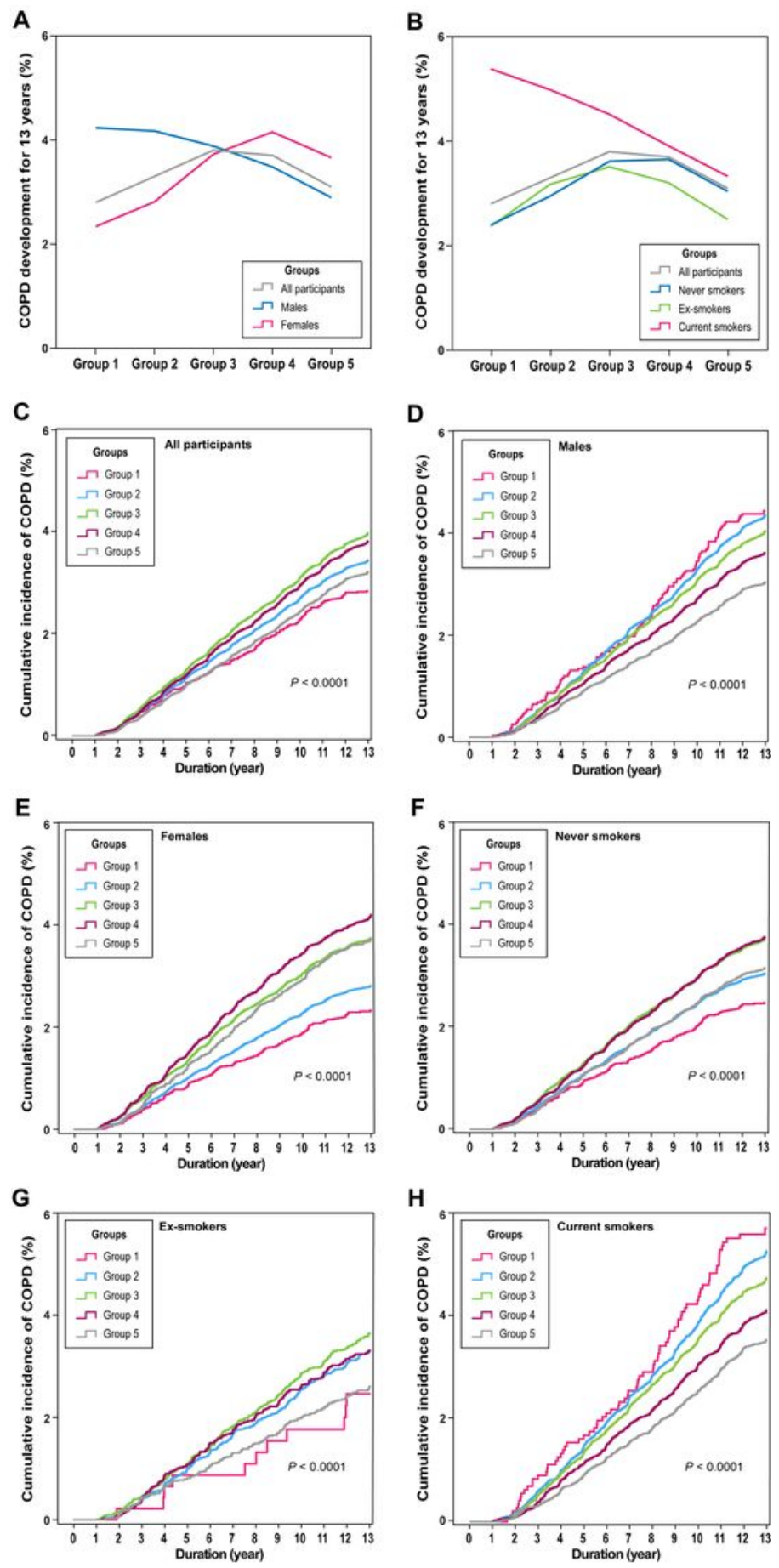

Figure 2

Prevalence and incidence of COPD development over 13 years. Prevalence of COPD development over 13 years according to sex (A) and smoking status (B). Kaplan-Meier curves for the cumulative incidence of COPD development over 13 years according to the ALT group. All participants (C), males (D), females (E), never smokers $(F)$, ex-smokers $(G)$, and current smokers $(H)$. ALT, alanine aminotransferase; COPD, chronic obstructive pulmonary disease. 
A

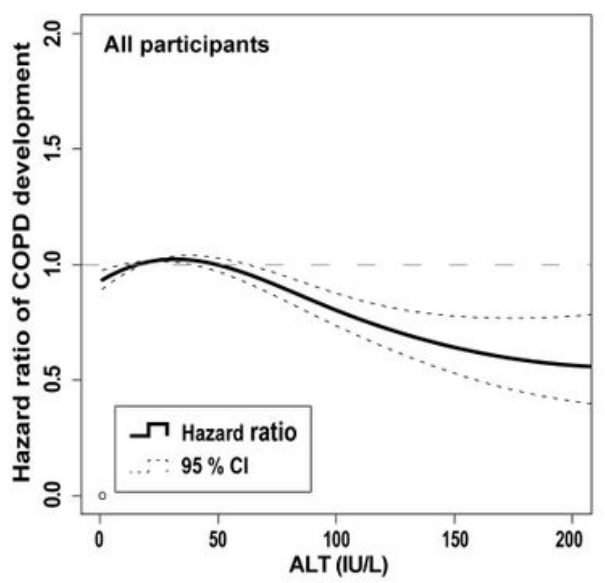

D

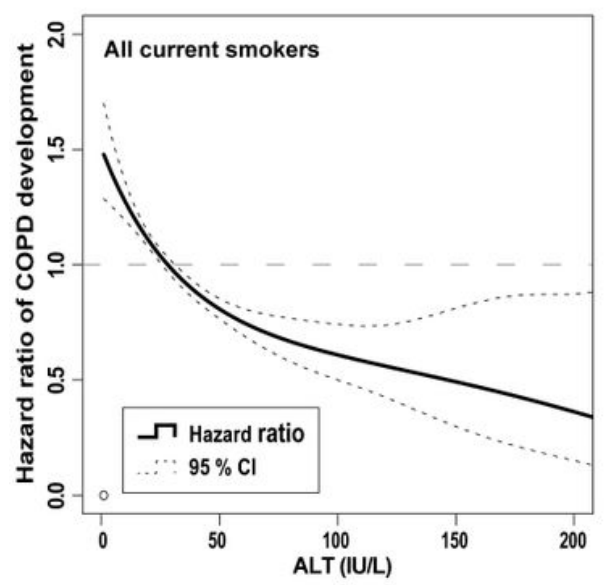

G

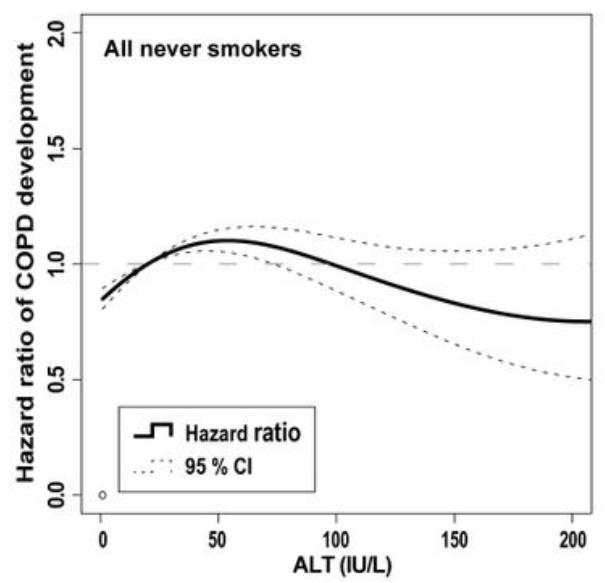

B

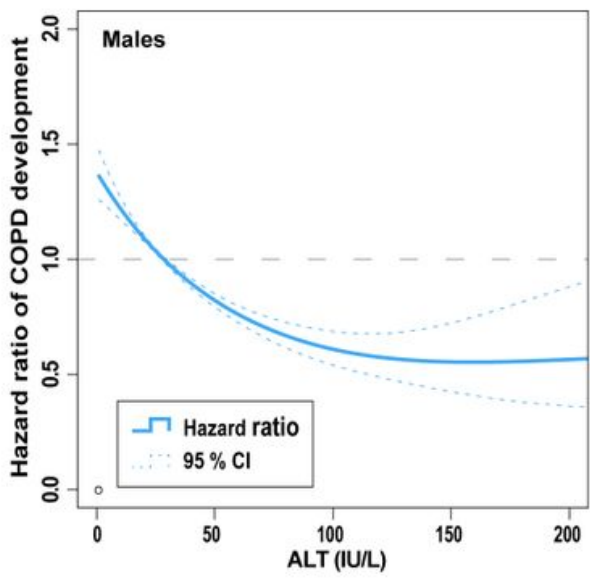

E

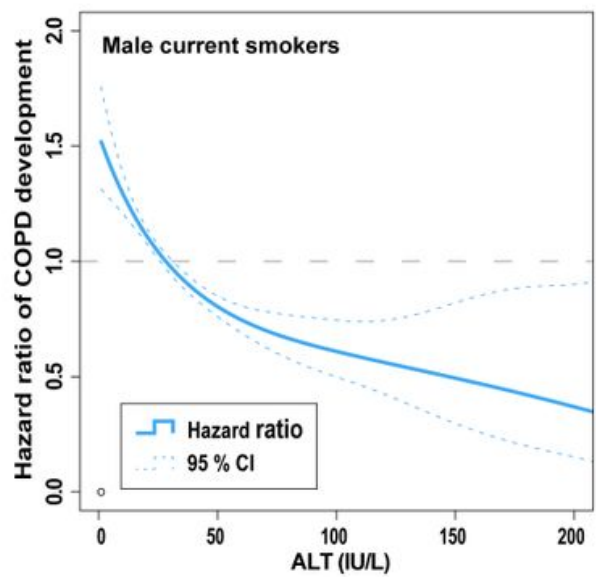

H

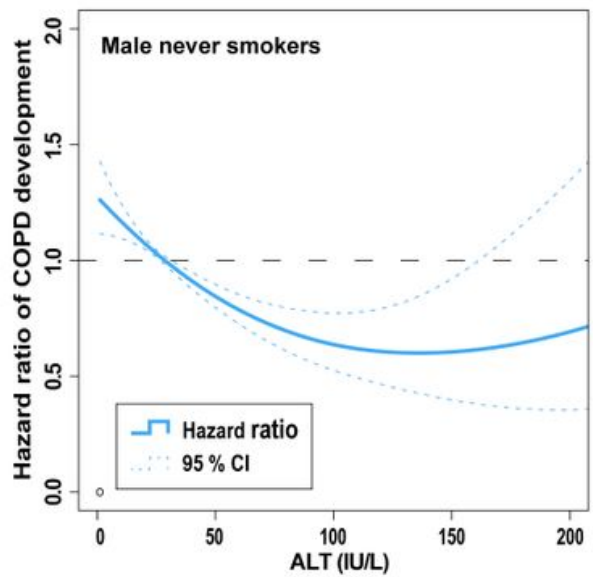

C

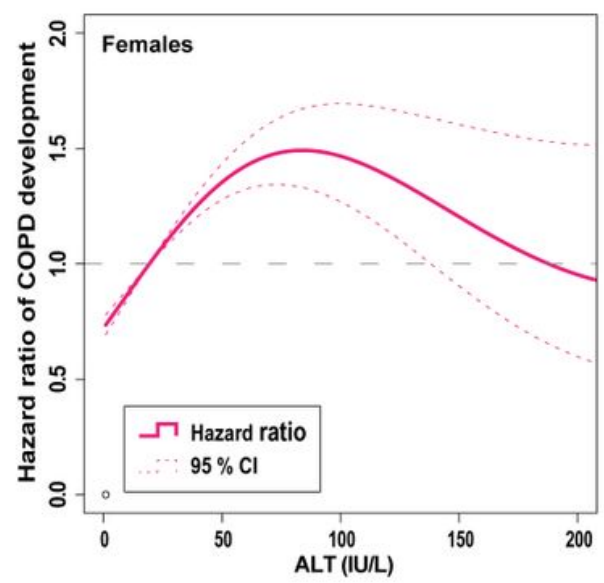

F

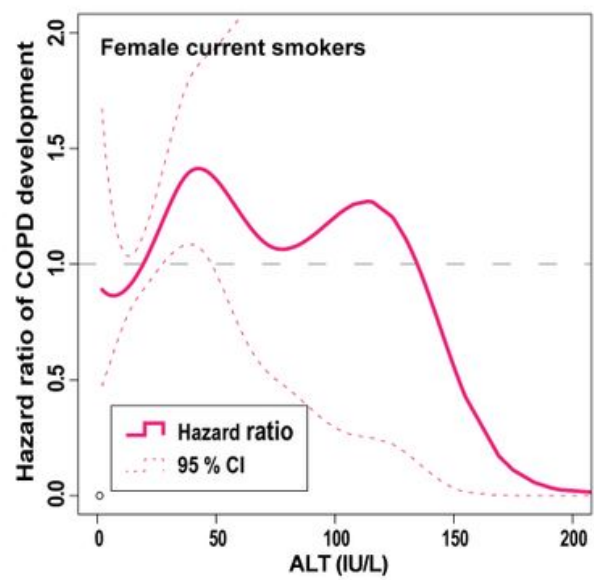

I

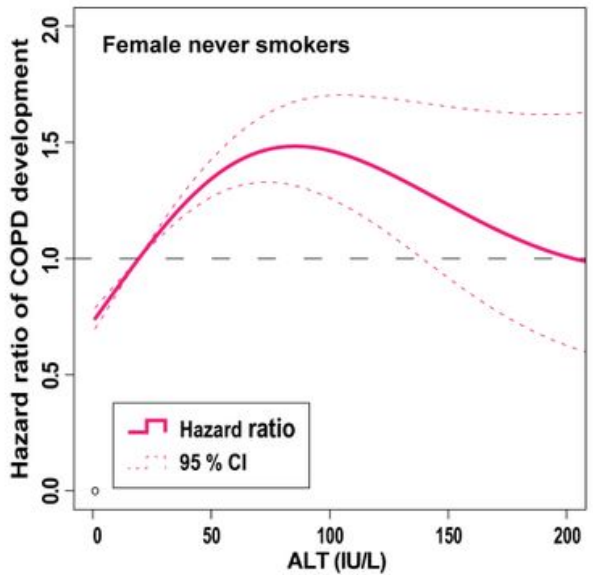

Figure 3

Spline curves of the hazard ratios for COPD development in all participants. (A), males (B), females (C), all current smokers (D), male current smokers (E), female current smokers (F), all never smokers (G), male never smokers $(\mathrm{H})$, and female never smokers (I). ALT, alanine aminotransferase; COPD, chronic obstructive pulmonary disease. 


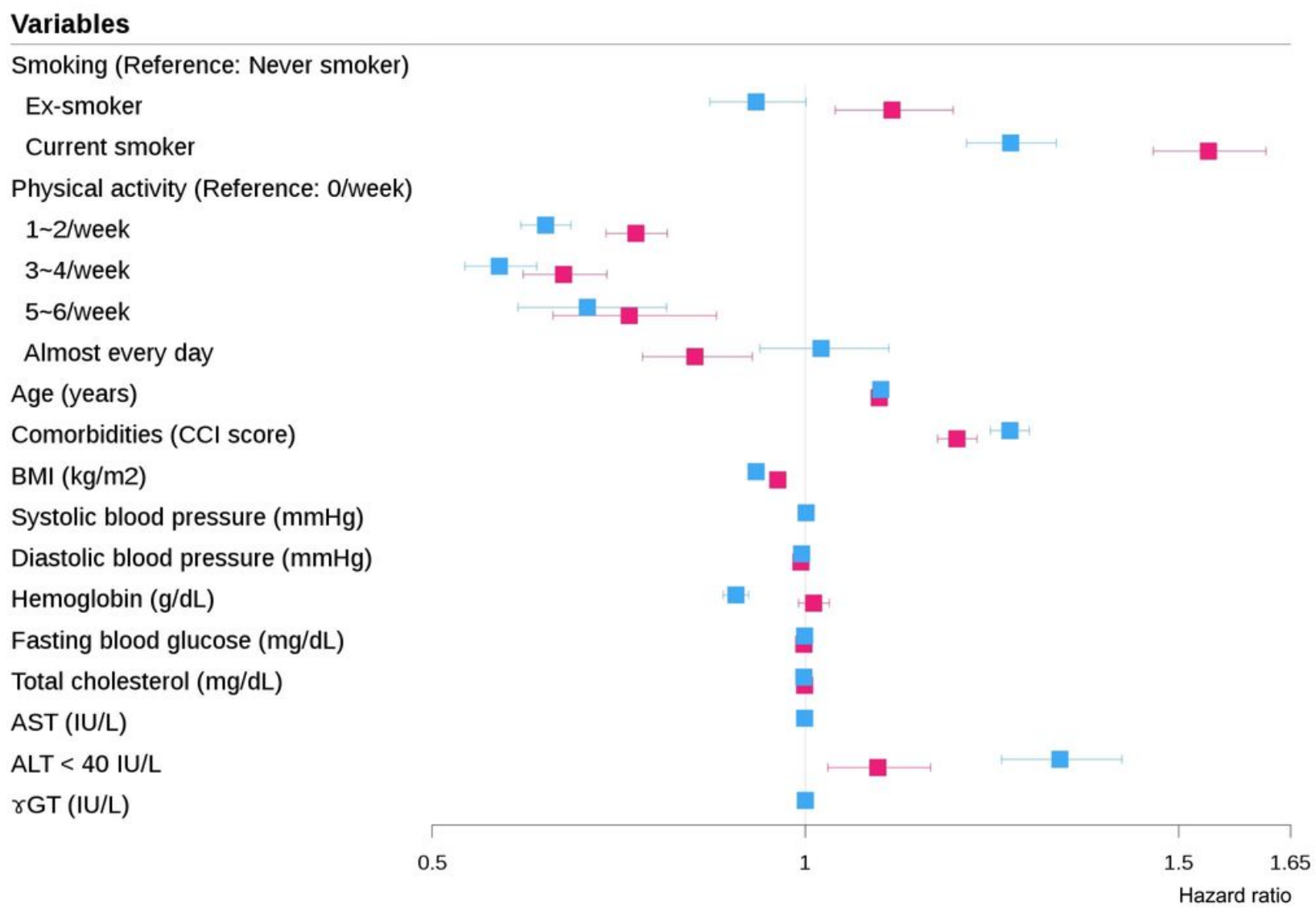

\section{Figure 4}

Hazard ratios for COPD development in males. COPD, chronic obstructive pulmonary disease; CCI, Charlson's comorbidity index; BMI, body mass index; AST, aspartate aminotransferase; ALT, alanine aminotransferase; $\llbracket G T$, gamma-glutamyl transferase. 


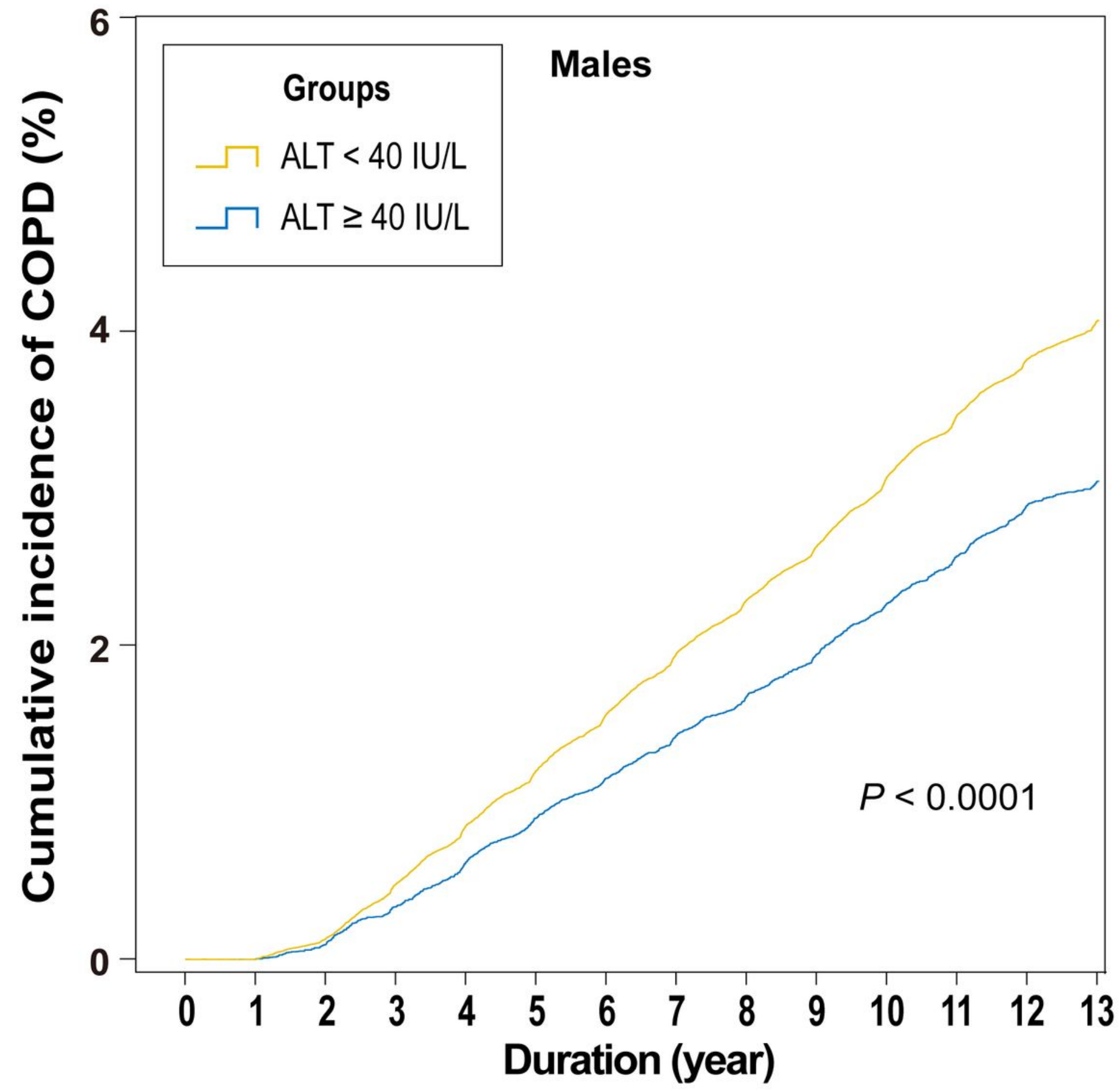

Figure 5

Kaplan-Meier curves of cumulative COPD development in males. ALT, alanine aminotransferase; COPD, chronic obstructive pulmonary disease.

\section{Supplementary Files}

This is a list of supplementary files associated with this preprint. Click to download. 
- SubmissiontemplateSupplementaryInformation.doc 